Author has nothing to disclose with regard to commercial support.

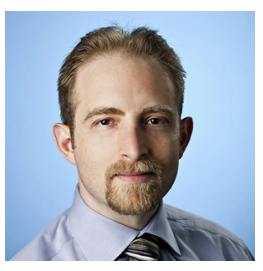

\section{ROUTINE INTRAVENOUS ACETAMINOPHEN FOR POSTCARDIAC SURGERY ANALGESIA: HIGH COSTS AND QUESTIONABLE BENEFITS}

To the Editor:

The management of postoperative pain after cardiac surgery remains a clinical challenging. Well-controlled pain can help facilitate early recovery and is critical to the physical and psychological well-being of each patient. Opioids are the medications most commonly administered to alleviate postoperative pain, but their use can be associated with challenging side effects. ${ }^{1,2}$ It was therefore with great interest that I read the recent report by Mamoun and colleagues ${ }^{3}$ describing their industrysponsored placebo-controlled clinical trial evaluating the use of intravenous acetaminophen for analgesia during the first 24 hours after cardiac surgery. ${ }^{3}$ In their single-center study, 147 patients were randomly assigned to receive $1 \mathrm{~g}$ of intravenous acetaminophen or placebo every 6 hours for 24 hours starting in the operating room. Mamoun and colleagues $^{3}$ observed that acetaminophen reduced mean pain scores (on a numeric pain scale that ranged from 0 to $10)$ by $0.90(P<.001)$. It did not, however, reduce postoperative opioid consumption or opioid-related side-effects, such as nausea, vomiting, or respiratory depression.

Before the availability of the study data of Mamoun and colleagues, ${ }^{3}$ my group recently published a systematic review on the use of intravenous acetaminophen after adult cardiac operations. ${ }^{4}$ In our review, which summarized 9 articles and data from 586 patients, we noted that when intravenous acetaminophen was added to a background of opioid therapy, minimal clinical benefits were noted-findings similar to those reported by Mamoun and colleagues. ${ }^{3}$ Moreover, we found that intravenous acetaminophen did not improve postoperative pain scores relative to oral or rectal administration of acetaminophen, irrespective of the higher and more rapid plasma concentrations achieved with intravenous acetaminophen. ${ }^{4}$

The question remains as to the current role for intravenous acetaminophen after cardiac surgery. In their article, Mamoun and colleagues ${ }^{3}$ concluded that "intravenous acetaminophen can be an effective analgesic adjunct in patients recovering from median sternotomy." 3 As noted in an accompanying editorial, however, intravenous acetaminophen is quite costly. ${ }^{5}$ In light of the marginal benefits noted in their trial ${ }^{3}$ and those reported by others, ${ }^{4}$ do Mamoun and colleagues believe that the costs justify the routine use of intravenous acetaminophen to all patients after cardiac surgery? Although their results achieved statistical significance, the clinical significance of a 0.90 reduction in pain scores is questionable. I would be pleased to learn whether they administer intravenous acetaminophen to all their cardiac surgical patients at present. Given the results of my group's systematic review, I believe that intravenous acetaminophen should be used selectively after cardiac surgery. ${ }^{4}$ In our experience, we limit its administration to select patients who are unable to tolerate oral analgesia during the first 24 to 48 postoperative hours because of severe nausea or ileus. We have also found it be helpful for the management of fever in the initial few hours after surgery and for older patients in whom concerns regarding excessive sedation or confusion limit the use of narcotics and oral analgesics if aspiration remains a risk.

Alexander Kulik, $M D, M P H$

Lynn Heart and Vascular Institute

Boca Raton Regional Hospital

Charles E. Schmidt College of Medicine

Florida Atlantic University

Boca Raton, Fla

\section{References}

1. Kulik A, Ruel M, Bourke ME, Sawyer L, Penning J, Nathan HJ, et al. Postoperative naproxen after coronary artery bypass surgery: a double-blind randomized controlled trial. Eur J Cardiothorac Surg. 2004;26:694-700.

2. Kulik A, Bykov K, Choudhry NK, Bateman BT. Non-steroidal anti-inflammatory drug administration after coronary artery bypass surgery: utilization persists despite the boxed warning. Pharmacoepidemiol Drug Saf. 2015;24:647-53.

3. Mamoun NF, Lin P, Zimmerman NM, Mascha EJ, Mick SL, Insler SR, et al. Intravenous acetaminophen analgesia after cardiac surgery: a randomized, blinded, controlled superiority trial. J Thorac Cardiovasc Surg. 2016;152:881-9.e1.

4. Douzjian DJ, Kulik A. Old drug, new route: a systematic review of intravenous acetaminophen after adult cardiac surgery. J Cardiothorac Vasc Anesth. March 16, 2016 [Epub ahead of print].

5. Varelmann DJ, D'Ambra MN. Big fish, little fish. J Thorac Cardiovasc Surg. 2016; 152:890.

http://dx.doi.org/10.1016/j.jtcvs.2016.09.006

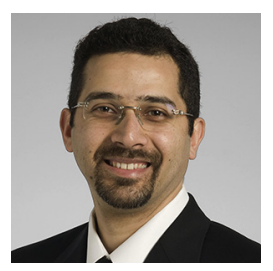

INTRAVENOUS

ACETAMINOPHEN: CAN

$\left(Q_{\text {crossMark }}\right.$

THE BENEFIT OUTWEIGH

THE COST IN SELECTED

PATIENTS?

Reply to the Editor:

Americans view the pharmaceutical industry negatively, surpassed only by their views of the oil and gas industry and the federal government. ${ }^{1}$ This sentiment is counterintuitive for an industry whose mission is to bring new cures to the public. Poor publicity may in part result from recent substantial and apparently unjustified increases in drug prices. Although the industry argues 
Author has nothing to disclose with regard to commercial support.

that it is costly to bring a drug to the market, we are currently witnessing soaring prices of off-patent drugs because of the lack of competition from generic versions-increases that are clearly unrelated to development costs and counter to the interests of patients.

Nevertheless, the purpose of our study was not to investigate the cost of intravenous (IV) acetaminophen use in cardiac surgical patients. Our investigation was designed to answer a specific question of whether IV acetaminophen improves analgesia after cardiac surgery. We assessed the effectiveness of IV acetaminophen (vs placebo) on pain management by measuring cumulative opioid consumption and pain intensity scores within the first $24 \mathrm{hr}$ after surgery using a joint hypothesis testing framework. We found that IV acetaminophen reduced pain intensity scores by about 1 point on a 0 to 10 scale, but did not significantly reduce opioid consumption after cardiac surgery. Clinicians (and supply chain managers) can use our clear results to make informed decisions about whether to use the drug. ${ }^{2}$

It is incumbent on all clinicians to be cost conscious when prescribing drugs. Indeed, a cost analysis would have been helpful, but would be challenging when the drug price is a moving target. Cost analyses are also complicated by the fact that various hospitals pay different amounts for the same drug, and those costs are often confidential. It is more appropriate to mention those concerns in other venues such as the accompanying editorial commentary. ${ }^{3}$ Ultimately, clinicians should consider cost when selecting among available drugs.

Our study demonstrated clinical benefit as determined by a priori criteria. However, the benefit was relatively small, and restricted to 1 of our 2 defined outcomes. We certainly do not interpret our results as a mandate for universal use of IV acetaminophen, especially given the broad range of alternatives. But the results will guide clinicians in choosing appropriate strategies for various patients. For example, selected patients may nonetheless benefit from IV acetaminophen, including the elderly who are at risk of excessive sedation with opioids or patients at risk of postoperative nausea and vomiting or ileus.

We use multimodal analgesia to control pain after cardiac surgery. ${ }^{4}$ Typically, we give acetaminophen orally or through an orogastric tube to provide background analgesia. Intravenous acetaminophen is substituted for the oral formulation in selected cases. Acetaminophen is often supplemented with nonsteroidal antiinflammatory drugs if appropriate, and opioids because acetaminophen alone usually does not provide sufficient analgesia after cardiac surgery. Our study results may help tailor the use of IV acetaminophen to the needs of patients who have undergone cardiac surgery by clearly quantifying its treatment effect. Despite its rising cost, IV acetaminophen may be beneficial in selected patients.

Negmeldeen F. Mamoun, MD, PhD

Departments of Cardiothoracic Anesthesia and Outcomes Research Anesthesiology Institute Cleveland Clinic Cleveland, Ohio

\section{References}

1. Norman J. Americans' views of pharmaceutical industry take a tumble. Available at: http://www.gallup.com/poll/185432/americans-views-pharmaceutical-industrytumble.aspx. Accessed September 14, 2015.

2. Mamoun NF, Lin P, Zimmerman NM, Mascha EJ, Mick SL, Insler SR, et al. Intravenous acetaminophen analgesia after cardiac surgery: a randomized, blinded, controlled superiority trial. J Thorac Cardiovasc Surg. 2016;152:881-9.

3. Varelmann DJ, D'Ambra MN. Big fish, little fish. J Thorac Cardiovasc Surg. 2016; 152:890.

4. White PF, Kehlet H, Neal JM, Schricker T, Carr DB, Carli F, et al. The role of the anesthesiologist in fast-track surgery: from multimodal analgesia to perioperative medical care. Anesth Analg. 2007;104:1380-96.

http://dx.doi.org/10.1016/j.jtcvs.2016.09.055 